\title{
Opsporing in verandering
}

\author{
E. van Zuidam*
}

\section{De crisis als keerpunt}

"De opsporing verkeert in een crisis". Dit zijn veel gehoorde woorden tijdens en na activiteiten van de commissie Van Traa. Hoewel voor velen deze stelling een negatief karakter draagt, wordt steeds duidelijker dat we in wezen met een zeer positieve transformatie van doen hebben; een transformatie van een deel van de overheid die absoluut noodzakelijk is voor beheersing van criminaliteitsproblemen in een complexe en dynamische maatschappij.

Het adaptieve vermogen van overheidsorganisaties is minder groot dan dat van profit-organisaties. De 'struggle for life' leidt door het overheidsmonopolie op bepaalde diensten niet tot gelijkmatige aanpassingen, maar tot pijnlijke schoksgewijze veranderingen. Vaak is een incident of een reeks incidenten noodzakelijk om onder druk van de publieke opinie een overheidsorganisatie, zoals de politie of het $\mathrm{OM}$, tot organisatorische veranderingen te dwingen. Zulke incidenten worden zelfs bewust georganiseerd en geregisseerd om een krachtige impuls te generen.

De crisis in de beheersing van openbare orde werd in de jaren '70 en '80 effectief beantwoord met een grootschalige ME-organisatie. Het onsamenhangende optreden van individuele politiemensen paste immers niet meer bij de verschijningsvormen van de ordeverstoringen. Later bleek ook die grootschalige ME-organisatie niet meer in staat om de doelstellingen te behalen.

Enige jaren geleden werd het accent verlegd van bestrijding van ordeverstoringen naar ordehandhaving. De diender moet weer communicatief worden met zijn omgeving om aankomende verstoringen in de kiem te smoren. Situaties die onder de norm duiken, worden snel 
'ingekapseld' door flexibele groepjes politiemensen met grote beslissingsbevoegdheid.

Ook in de opsporing hebben we kunnen zien dat bepaalde gebeurtenissen leiden tot keerpunten. Wij hadden de IRT affaire, de Italianen de moord op rechter Falcone, de Belgen Dutroux. In feite kunnen al dit soort incidenten gebruikt worden om noodzakelijke veranderingen een duwtje te geven.

\section{Maatschappelijke veranderingen}

Maar wat zijn nu zoal de maatschappelijke veranderingen, die aanpassingen van het opsporingsapparaat noodzakelijk maken? Belangrijk zijn onder andere:

- het wegvallen van het ijzeren gordijn

- het openstellen van de grenzen binnen de EU

- het explosieve karakter van technologische ontwikkelingen (bruikbaar voor criminelen en politie)

- grote veranderingen in de aard van het betalingsverkeer

- vergaande segmentering van de samenleving

- toenemende privatisering van overheidstaken

- verschuiving van inhoud naar verpakking (bijv. in de politiek)

- veranderende demografie (meer ouderen en allochtone Nederlanders)

- culturele veranderingen in samenleving, bv toenemende individualisering en een teruglopende rol voor de traditionele geloofsgemeenschappen.

Stellig zijn er nog vele andere trends te ontdekken die hun weerslag hebben op de politie-organisatie en haar taakuitvoering.

\section{Objectieve en subjectieve veiligheid}

Het begrip 'veiligheid' valt moeilijk te definiëren. Het probleem van de politie om haar core-business handen en voeten te geven hangt hiermee samen. 'Veiligheid' is één van die vage begrippen die tot de basis- 
taak van de overheid worden gerekend. De politie wordt geacht producten te leveren die het niveau van veiligheid positief beïnvloeden.

Veiligheid kan in hoofdlijnen op twee manieren worden beschouwd: objectief - met behulp van harde cijfers - en subjectief. In het laatste geval spreken we vaak over veiligheidsgevoel. Een absoluut veiligheidsgevoel bestaat niet. Jongeren beleven criminaliteit anders dan bijvoorbeeld ouderen of ondernemers. Zelfs binnen één persoon kan het veiligheidsgevoel variëren met de rol die hij vervult.

Ook bij objectieve veiligheid spelen subjectieve elementen overigens een rol. Degenen die de harde cijfers interpreteren, analyseren en waarderen hebben immers hun eigen referentiekaders. Hierdoor blijft ook de vertaling van cijfers naar politie-activiteiten een subjectieve actie.

\section{Politiek vraagstuk}

De beoordeling van veiligheid en de vaststelling van prioriteiten in het politie-optreden is meer dan ooit een politiek vraagstuk. Iedereen vindt de aanpak van fietsendiefstal belangrijk als zijn fiets net is gestolen. Maar is net een gezinslid aangereden door een te snel rijdende automobilist, dan moeten snelheidscontroles ineens weer prioriteit krijgen. Ook het feit dat criminaliteit voor een deel voortvloeit uit politiek handelen maakt het vaststellen van prioriteiten een politieke aangelegenheid. Verderop in deze beschouwing meer daarover.

In de rest van deze beschouwing wordt het begrip 'veiligheid' geconcretiseerd aan de hand van de aanpak van criminaliteit. Andere veiligheidsclusters zoals de veiligheid in het verkeer en de veiligheid op de werkplek laten we buiten beschouwing.

\section{Aanpak van criminaliteit}


De aanpak van de criminaliteit gebeurt op verschillende manieren. Ik noem hier vier manieren van aanpak waarbij de politie actief kan zijn:

\section{Schuiven met de formele norm}

De formele norm staat ter discussie, omdat deze niet meer bij de omgeving past. Daaruit vloeit de vraag voort: heeft handhaving en opsporing nog wel zin?

Twee oplossingen zijn mogelijk:

- aanpassing van het wettelijk kader (input voor het politiek en wetgeving);

- uitvaardiging van richtlijnen hoe om te gaan met handhaving en opsporing (gedogen).

Deze methode lijkt typisch Nederlands: verbieden, maar niets doen bij overtreding. Het schetst de worsteling van de overheid met de complexe en politiek gevoelige materie. Er zijn vaak te veel belangen betrokken om de materie in eenvoudige regeltjes te vatten. Voorbeelden: Milieucriminaliteit versus werkgelegenheid en drugscriminaliteit versus volksgezondheid.

\section{Bestuurlijke preventie}

Steeds duidelijker wordt dat bestuurlijke actie of nalatigheid crimineel gedrag c.q. een onveilige situatie bevordert en soms zelfs uitlokt. Als voorbeelden kunnen worden genoemd:

- planologische missers (bv enge plekken)

- een onjuist vergunningenbeleid

- ontbrekende samenhang in beleid bij de verschillende onderdelen van het bestuur (gemeentelijke, provinciale diensten, departementen)

- gebrek aan strategische visie in relatie tot maatschappelijke trends

- gebrek aan integriteit.

\section{Beïnloeding van de maatschappij}

Socio- en technopreventieve acties kunnen het criminaliteitsniveau beïnvloeden. Nadeel van dit soort benaderingen is, dat door potentiële daders vaak naar alternatieve mogelijkheden c.q. delictsvormen wordt 
gezocht. Na de beveiliging van bankgebouwen en grootwinkelbedrijven zag men een toename in de overvallencriminaliteit op cafetaria's, pizzabezorgers en kleine ondernemers. Ook werden overvallen gepleegd op woningen (inbraakpreventie is nu eenmaal geen overvalpreventie) en steeg de straatroof.

\section{Beïnvloeding van daders}

Beïnvloeding is natuurlijk slechts mogelijk indien de daders geïndividualiseerd onder invloed van de overheid komen. Het opsporingsproces is daarvoor een krachtig middel. Als vervolg op dit opsporingsproces kunnen verschillende reacties vanuit de overheid gegeven worden. De aard van de reactie krijgt onder invloed van de maatschappelijke ontwikkelingen steeds meer het karakter van maatwerk. Hoewel ook andere organisaties actief zijn in het opsporen van daders behoort met name de politie-organisatie hier te presteren.

\section{Criminaliteitspiramide}

Er valt een aantal criminaliteitsniveaus te onderscheiden: het niveau van de veel voorkomende criminaliteit, dat van de lokaal ernstige criminaliteit en dat van de zware criminaliteit. Deze niveaus vallen wel te onderscheiden maar kunnen bij de aanpak niet gescheiden worden.

Een duidelijk voorbeeld ligt bij de verdovende middelen.

- De Groninger junk op straat veroorzaakt overlast en breekt in. Hij betrekt zijn dope van een eveneens verslaafde consumptie-dealer.

- Deze consumptiedealer combineert vaak zijn 'vak' met de heling van goederen. Hij betrekt zijn 'grammen' van de brood-dealer.

- De brood-dealer betrekt zijn 'pondjes' van de distributie-dealer/importeur uit bijvoorbeeld Amsterdam.

- De dealer uit Amsterdam betrekt zijn 'kilo's' van de exporteurs in het buitenland.

Hier wordt de verbondenheid van zware misdaad met de middelzware en de veelvoorkomende criminaliteit uitgebeeld. Voor dit beeld wordt bij de Nederlandse politie veelal de vorm van een piramide gekozen. Aan de hand van deze piramide kan gezegd worden dat de taken 
binnen het regiokorps dat belast is met de primaire opsporingstaak effectief en efficiënt moeten worden verdeeld. Vervolgens moet alle aandacht gericht worden op samenhang in de informatievoorziening en aanpak van de geconstateerde criminaliteitspatronen. Uitgangspunt moet daarbij zijn dat de politie-organisatie centraal en decentraal zodanig wordt ingericht, dat er bij de opsporingstaak sprake is van kwalitatieve probleemherkenning, analyse en aanpak.

\section{Wijk, district en regio}

De opsporing in de regiokorpsen wordt op regioniveau geoperationaliseerd door een centrale divisie zware criminaliteit, op districtsniveau - een cluster van gemeentes - en op lokaal c.q. wijkniveau in de vorm van eenheden belast met de lokale politiezorg.

De lokaal ingerichte politiezorg is bij uitstek geschikt voor de aanpak van de veel voorkomende criminaliteitsproblemen. Deze recherchefunctie kan dus in uniform worden uitgevoerd. Dit verhoogt de zichtbaarheid van de politiezorg en geeft toe aan de roep om meer 'blauw' in het zicht van de burger. De verdere schaalverkleining in de basispolitiezorg zal bovendien de informatiepositie van de politie in de haarvaten van onze maatschappij verstevigen. De politie signaleert dingen sneller; dit kan de aanpak van (middel-)zware vormen van criminaliteit ondersteunen.

Op districtsniveau zijn recherche-eenheden belast met de zogenaamde middelzware criminaliteit. Daders in deze 'middencriminaliteit' vertonen wel recidive maar voldoen veelal niet aan de wezenlijke kenmerken van een organisatie. Het gedrag van deze criminelen vloeit meestal voort uit de 'lagere' behoeften.

Op regionaal niveau zijn de divisie zware criminaliteit, de IRT's en het landelijk rechercheteam primair belast met de aanpak van de zware criminaliteit. De zware criminaliteit komt later in dit artikel overigens nog uitgebreid aan de orde.

De recherchetaak op lokaal, districts- en regionaal/nationaal niveau dient nauw aan te sluiten bij het werkterrein van de betreffende organisatorische eenheid. Criminaliteitsproblemen met een nationale/regionale dynamiek dienen niet tot de taak van de lokale zorg gere- 
kend te worden, terwijl problemen met een reikwijdte op lokaal c.q. wijk-/buurtniveau niet nodeloos tot regionale aanpak moeten leiden. Dit betekent dat voor de opsporingstaak het thans veel voorkomende principe: 'zoveel mogelijk decentraal', wordt ingewisseld voor: 'probleemaanpak op het meest effectieve en efficiënte organisatorische schaal'.

\section{Samenwerking}

Gelet op de complexiteit en verwevenheid van criminaliteitsproblematiek dient, zowel uit oogpunt van efficiency als ten behoeve van kwaliteit en continuïteit, de samenwerking met handhavings- en opsporingspartners (FIOD, ECD, Milieu-inspectie etc.) te worden geïntensiveerd. Eerder beschouwde de politie deze partners vooral als ongewenste pseudo-politie-organisaties. Tegenwoordig breekt steeds meer het besef door dat deze organisaties hun eigen expertise kunnen inbrengen.

\section{Dimensies van criminaliteit}

Terugkomend op de criminaliteitspiramide kan in algemene zin gesteld worden dat de piramide meerdere criminaliteitsdimensies symboliseert, namelijk: omvang, ernst, geografische dynamiek en zichtbaarheid van de criminaliteitsproblemen.

Zo zijn er personen die carrière maken op de criminele ladder. Neem bijvoorbeeld jongelui die beginnen als 'vandaaltje' en daarna gaan inbreken om vervolgens vatbaar te worden voor de verlokkingen van meer georganiseerde c.q. professionele vormen van misdaad. Het is echter niet noodzakelijk om onderaan de piramide te beginnen. Aanvankelijk volledig rechtschapen mensen (bijv. ondernemers) kunnen onder druk van de maatschappelijke of persoonlijke situatie betrokken raken bij zware vormen van criminaliteit.

Naast daderspecifieke elementen, illustreert de piramide de aanwezigheid van maatschappelijke problemen, die met elkaar verbonden zijn. Er zijn clusters van problemen in de samenleving die zich uiten 
op diverse criminaliteitsniveaus. In de Mercatorbuurt in Amsterdam

bleken vormen van zware, middelzware en veel voorkomende criminaliteit op een complexe wijze met elkaar verbonden.

\section{Nieuwe probleembenadering}

Het toepassen van moderne theorieën over de complexe criminaliteitsproblematiek zou wel eens een doorbraak kunnen betekenen. Analyse van de complexiteit en herkenning van achterliggende systemen kan de weg openen naar een meer fundamentele en geïntegreerde aanpak van het probleem. Essentieel is het herkennen van dominante stabiliserende of katalyserende factoren in de achterliggende systemen. Gerichte actie op deze factoren kan leiden tot effectieve desintegratie van het systeem.

In deze zin is het opmerkelijk dat criminologen, gunstige uitzonderingen daargelaten, slechts aarzelend overgaan tot een meer systeemen procesgericht denken. Hun collega's in de biologie, economie, natuurkunde, meteorologie, organisatie- en bestuurskunde gaan in dit opzicht voortvarend te werk. Het zou jammer zijn indien de nadruk te veel blijft liggen op het reductionistisch ontleden en verklaren van criminaliteitsproblemen op het niveau van verschijningsvormen (oorzaak-gevolg relaties) en persoonlijkheidsfactoren.

\section{De complexiteit van de zware criminaliteit}

Laten we wat langer stilstaan bij de zware criminaliteit. Al geruime tijd is duidelijk, dat georganiseerde misdaad in Nederland alle organisatiemodellen aanneemt die ook in het legale bedrijfsleven naar voren komen. Er zijn weinig multinationals, veel midden- en kleinbedrijven en de marktsegmenten worden beheerst door samenwerking en jointventures.

Al deze 'organisaties' proberen in te spelen op vraag en aanbod. Ze proberen de kwaliteit van hun handelen te verhogen door het inhuren 
van de juiste expertise: financiële (geldstromen, investeringen, witwasconstructies), technologische (communicatie, verpakkingen) en juridische expertise (constructies, 'verzekeringen'), naast expertise op het gebied van transport, distributie en research (chemische drugs).

De wereld van Al Capone was duidelijk. Hij gaf leiding aan een goed gestileerde organisatie. De realiteit voor de politie is weerbarstiger. Artikel $140 \mathrm{WvSr}$ (deelnemen aan een criminele organisatie) is lastig in een proces-verbaal te verwerken.

Politiemensen, advocaten, officieren van justitie, rechters en wetgevers hebben ieder hun eigen beeld over de reikwijdte van het begrip 'organisatie'. In de registers van de Kamer van Koophandel staan vele éénmens-organisaties. Zou het 'deelnemen aan een crimineel bedrijf' wellicht een doeltreffender begrip zijn?

\section{Vormen van zware criminaliteit}

Onder zware criminaliteit wordt door de politie begrepen:

\section{Georganiseerde criminaliteit}

Onder 'georganiseerde criminaliteit' verstaan we organisaties die actief zijn op illegale markten, bijvoorbeeld drugs, vrouwenhandel, orgaanhandel en uitstervende diersoorten. We noemen dit de 'onderwereld'. De onderwereld zal altijd de ambitie vertonen om zich te nestelen in de legale bovenwereld. Dit geeft aanzien, macht en comfort. Zaken doen - bijvoorbeeld geld investeren - wordt er bovendien een stuk gemakkelijker van.

\section{Organisatiecriminaliteit}

Organisatiecriminaliteit is het systematisch bedrijven van criminele activiteiten door legale organisaties, die ondernemen in de volle maatschappelijke schijnwerpers. Sommige vormen van organisatiecriminaliteit worden ook wel 'façade-criminaliteit' genoemd, omdat de legale onderneming enkel een dekmantel is voor de hoofdactiviteit: voordeel halen uit criminaliteit.

Een meer voorkomende vorm van organisatie-criminaliteit betreft het structureel plegen van criminele feiten in een of meer delen van het 
bedrijfsproces, waardoor het persoonlijk of bedrijfsgewin wordt verhoogd. Voorbeelden zijn: het zich illegaal ontdoen van afval, het structureel werken met zwartwerkers en het transportbedrijf dat ook voor drugsimporteurs werkt.

Bij organisatiecriminaliteit wordt vaak gebruik gemaakt van 'service' uit de onderwereld.

\section{Professionele criminaliteit}

Met deze term wordt de intellectuele misdaad bedoeld. Voorbeelden zijn de superfraudeur, hacker en de biotechnoloog die zich met verboden genetische manipulatie bezighoudt. Vaak zijn deze professionals facilitair aan bovenstaande zware criminaliteitsvormen.

\section{Onderwereld en bovenwereld}

Indien men de drie bovenstaande vormen nog eens nader in relatie tot elkaar beschouwt, ziet men een proces van een klimmende 'zwarte' onderwereld en een wegzakkende 'witte' bovenwereld. De professionele criminelen vormen, niet gehinderd door enige normen en waarden, in dit proces de rol van katalysator. De strategie van de recherche-eenheden op (inter)regionaal en landelijk niveau dient erop gericht te zijn dit proces te frustreren. Een toenemende 'vergrijzing' van de maatschappij - als resultaat van een verstrengeling van onder- en bovenwereld - tast de grondvesten van onze samenleving aan. Italië gaf vroeger het slechte voorbeeld, de Russische republiek doet dat momenteel.

\section{Aanpak verstrengeling}

De verstrengeling van onder- en bovenwereld moet op meerdere fronten bevochten worden. De politie beperkt zich niet meer tot informatiekanalen in de onderwereld, maar benadert ook gericht de relevante sectoren in het bedrijfsleven, bestuur, politiek en wetenschap. Het wordt zaak dat de recherche zich niet alleen richt op de traditionele misdaad (bijvoorbeeld de import van drugs), maar ook 
leert acties te ondernemen tegen vormen van organisatiecriminaliteit.

Die aanpak is voor de gemiddelde rechercheur geen sinecure en wellicht daarom bij veel van hen niet populair.

Maar de vertederende wiz-kids van vandaag zijn de professionals van morgen. Een gedeelte van hen zal aan de verkeerde kant gaan staan. In een maatschappij die volledig afhankelijk wordt van de computer (betalingsverkeer, bedrijfsinformatie, nutssystemen) zijn de risico's groot voor een te lakse samenleving en haar individuele leden. Wie bekommert zich over die verrassend onverwacht hoge telefoonrekening van die technologisch niet zo onderlegde burger?

Professionals bestrijd je met professionals. Een enorme kwaliteitsinjectie is daarom noodzakelijk. De politie-organisatie behoort aan het front te staan van de maatschappelijke innovaties en ontwikkelingen. Samen met de wetenschap - criminologen zouden hier een coördinerende rol kunnen innemen - moeten toekomstscenario's gemaakt worden. Die scenario's moeten vervolgens aan beleidsmakers worden gepresenteerd. 
De repressieve benadering van criminaliteit is uiteindelijk geen echte oplossing voor de problemen. Als een lichaam ziek is, zal een penicillinebehandeling alleen de symptomen bestrijden, terwijl het lichaam op zichzelf niet gezonder wordt. Sterker nog, de bacteriën krijgen kans om te muteren op basis van de bestrijdingsmethodes, waardoor het probleem op termijn wellicht zelfs zal escaleren. Het lichaam zal dus een grotere weerstand moeten krijgen om ziekmakende bacteriën geen kans te geven.

Trekken we een parallel naar de maatschappij, dan kan men stellen dat het opsporen en vastzetten van criminelen het probleem niet in de kern aanpakt. Er moet iets worden gedaan aan de weerstand van die maatschappij. Bij het openbaar bestuur betekent dit een noodzakelijk streven naar kwaliteit en integriteit. Corrupt gedrag, duistere inner-circles en old-boys-networks moeten worden tegengegaan. Geeft de overheid een slecht voorbeeld dan leidt dat tot verlaging van het normbesef van vele burgers. Dit is funest voor de weerstand van de maatschappij.

Ook de integriteit van het bedrijfsleven behoeft aandacht. Verhoging van winstmarges door een oog dicht te knijpen leidt niet alleen tot oneerlijke concurrentie en verstoring van de markt, maar ook tot 'noodgedwongen' navolging. Waarom zou een bedrijf zijn afval naar een legale afvalverwerker brengen als de illegale verwerker het voor een kwart van de prijs doet?

\section{Individu}

Tenslotte heeft de maatschappelijke weerstandsverbetering te maken met het normbesef van ieder individueel lid van onze maatschappij. Iedereen die zich geschokt toont over allerhande vormen van criminaliteit, zal zich eerst af moeten vragen hoe het zit met zijn eigen normen en waarden en met het consequent naleven daarvan. Hoe gaan we bijvoorbeeld om met de belastingen, de verkeersveiligheid, het milieu, illegale gegevensdragers, wetenschappelijk plagiaat? Kopen we graag kleding voor een prijs, die slechts dankzij illegale naai-ate- 
liers bewerkstelligd kan worden? Laten we die oprit toch maar leggen

door de 'beun'? Welk voorbeeld geven we aan de kinderen?

Kortom: Hoe 'grijs' zijn we eigenlijk zelf? 
